\title{
AN INTERNET OF HUMAN (IOH) FrameWORK FOR IMPROVING HEALTHCARE BUSINESS MODELS
}

\section{Homeira Moghadami ${ }^{*}$, Mahmood Kharrat ${ }^{1}$}

${ }^{1}$ ICT Research Institute, Tehran, Iran.

\begin{tabular}{|c|c|}
\hline Article & B S T R A \\
\hline & \multirow{3}{*}{$\begin{array}{l}\text { Introduction: } \\
\text { The World Health Organization's theme "Health for All" in } 2018 \text { is aimed at } \\
\text { achieving all countries' sustainable development goals and moving to } \\
\text { development priorities, Equity and social coherence. Achievement of these } \\
\text { goals is associated with challenges such as resource scarcity, changing } \\
\text { priorities, continuing demands from the community, and economic crises. } \\
\text { The use of Internet technologies as one of the most important trends in the } \\
\text { quality of services and the effectiveness of the health system is a solution to } \\
\text { the above challenges. After the first generation of the Internet, refers to } \\
\text { Internet of Digital (IoD), and the second one, Internet of things (IoT) that } \\
\text { have extensively influenced various aspects of human life such as education, } \\
\text { energy, health, transport, a new interpretation as the third generation } \\
\text { Internet is the Internet of Humans (IoH), which is a form of co-existence of } \\
\text { humans and IoT devices. In this way, the Internet will not only be used as a } \\
\text { practical tool, it will be part of us. The logic of this type of Internet, with its } \\
\text { connectivity and the interconnection of all stakeholders, is the human- } \\
\text { centric approach and leads to serve without harmful constraints to the } \\
\text { people and society. In this generation, the Internet is used for important } \\
\text { targeting and solving the world's greatest challenges. }\end{array}$} \\
\hline $\begin{array}{l}\text { Article History: } \\
\text { Received: } 2018- \\
\text { Revised: } 2018-1 \\
\text { Accepted: } 2018-\end{array}$ & \\
\hline $\begin{array}{l}\text { ICT research Institute, Tehran, } \\
\text { Email: moghadami@ict.ac.ir }\end{array}$ & \\
\hline
\end{tabular}

\section{Material and Methods:}

In this paper, a framework for the Internet of Humans ( $\mathrm{IOH})$ will be presented, which will take a great look at the health field, particularly in terms of the of new business models. As developing the IoH and the new health-related business models based on this technology, various concerns about provide an integrated framework for this issue have emerged, which has led to the emergence of extensive research in the world, particularly in the European Union.

\section{Results:}

Within the proposed framework, the key enablers (such as IoT, cloud computing, artificial intelligence, etc.) with key controllers (such as security, privacy, investment, etc.) creates new e- health business models. The most important result presented in this framework is the consideration of human factors in the development of new business models from the beginning of the business development process.

\section{Conclusion:}

The proposed framework, considering human factors in the development of business models, will lead to the possibility of offering new products and services, different industries, changing the value of the industries, changing the identity of the focus point. It also makes it possible to define a new role or value for data, processes, and infrastructures, and ultimately to differentiate how health services are performed.

Keywords:

IoH, Frame work, Business Model

How to cite this paper

Moghadami H, Kharrat M. An Internet of Human ( $\mathrm{IoH}$ ) Framework for Improving Healthcare Business Models. Front Health Inform. 2019; 8(1): e3. DOI: 10.30699/fhi.v8i1.156 


\section{INTRODUCTION}

The concept of development in the information age has been transformed by the transition from industry centric to information centric. This all-round change transforms all other dimensions of life. This change has led a big revolution in addition to the concept of development and their models (including development goals and tools), our understanding of the dimensions of development (e.g., economic, human, political, etc.), and how they are realized.

"Informational Development," is the most significant development models in the information age, in which fundamental transformation takes place in all dimensions, goals, and development tools. This emerging pattern has undergone a major transformation not only in the pattern of economic development, but also in many other aspects of development, including human development. Therefore, solutions to the development of information can be addressed to developmental issues and challenges [1]].

One of the challenges of human development in the information age is promoting health and improving access to basic needs and social welfare. Rapid growth of information and communication technologies, the emergence of widespread social networks and the global interconnection of economies and societies in the information age, bring solutions with multidimensional and comprehensive approaches in pursuit of health-centered goals of sustainable development. Health as the key to the realization of sustainable development is a prerequisite, but also an indicator in all economic, social and environmental dimensions of achieving sustainable development, because other issues such as economic problems, lack of awareness, misleading lifestyles and illiteracy are the factors that directly affects people's health [2]].

ICT, as an accelerator of profitability and differentiation in the market and industry, has led to a huge transformation in various sciences, industries and services. E-health is one of the new areas that have emerged in the age of communication. With the advent of advanced technologies, the health sector has moved towards serving these emerging technologies. The issue of health and the creation of the necessary infrastructure for access to all individuals is a vital and impregnable task for the policymakers, the government, social institutions, the media, and even the ordinary people of society. The Internet is one of the most important infrastructures that people, are the stakeholders, even its main actors, providing value with the highest level of participation. Everyone in the community has a share on the Internet, and for this reason it has to go the way that human uses its services to meet her needs.
On the one hand, the Internet in the health care system has led to increase productivity and widespread health ecosystem for business actors and service providers, on the other hand, it has led to increased consumer awareness. Connected Patients change the balance of power. Internet providers also transform Working methods; as a result of these changes, the dynamics between patients and providers is changed in the health ecosystem []].

The challenge that comes about in the near future is how can the health industry meet the expectations of such patients, which has changed dramatically in their identity? The new generation of the Internet IoH, will play an important role in this arena, with a value-based approach. The health industry will be able to support the rights of the human potential of the Internet, with regard to changing values and changing the identity of patients as customers while providing human-centric services [4]].

\section{Internet of Humans ( $\mathrm{IoH})$}

In the coming decades logic, architecture, and the Internet interface will have shaped human interactions with a networked world. The new geometry of the Internet will place humans at the center. The human worlds are redesigned and rebuilt to fit its natural dimension. Such an Internet of human will increase and strengthen the mental and physical health of humans.

At the core of the new human Internet are four new potentials []ㅡ:

- The capacity for flow: Technologies that work together to create a seamless environment for human interaction.

- The ability to sense: human -machine interconnections intangibly provide the ability to understand all human emotions.

- $\quad$ The facility to control: The capabilities needed to direct, modify, and restrict the internet are always organic and dynamic.

- The proclivity to emerge: Like the Internet, it abandons itself from the creators and constructor.

Given the diversity IoT features, the current business models will not necessarily be able to support this emerging phenomenon. The Internet of humans will have a significant impact on the social economy as it manages to deal with emerging concepts such as patient-centered, self-aware patients, the importance of patient digital experience, participatory strategies between patient/client and provider.

Health information is heavily in need of strong support and management, with a great deal of time and expense, due to the large number of stakeholders involved in all types of countries. Understanding the 
different dimensions of the current Internet (IoT) it will help human society use it more effectively to improve and promote the health.

\section{Internet of Things (IoT):}

Communicational network of IoT ecosystem uses Internet, cloud-based services, datacenters, and data transfer technologies, and many tools and applications to control, manage, and service objects. Each solution offered by the IoT includes five elements; such as platforms, ICT access technologies, data storage and processing, data analysis and security [ㅁ] .

The gap observed in this regard is the human category and its values, which will turn into great society challenges in the near future. Considering the stimuli of change and the affected areas as two interconnected factors on the Internet are some of the things that can help explain human status.

Drivers of change are forces that are known as the drivers of future change and the Internet, and also effective in human development in the future. These include the Internet and the physical world, artificial intelligence, cyber threats, Internet economy, networks, Standards and Interoperability and the role of governments. These interacting drivers are faced with challenges such as technological, economic, legal, security and network challenges that affect the future of the state of the Internet.

\section{Areas of Impact}

The human community regards these drivers from the point of view to the effects of digital divide, Personal freedoms and rights, and media and society. These areas have been targeted in the focus of attention of the users at the core of the Internet. The abilities of users to connect, share, to innovate, to choose the Internet-related services and information, and to trust in the network are all influenced by the drivers of future Internet change []ㅡ. For example, if it is supposed all parts of the world economy are to transform through the Internet, then the question is whether the benefits of this economic transformation will be for all segments of the population or just for some parts of the world? The answer to this question refers to the digital divide component. Here, for a more complete understanding of the subject, we examine the pillar of the global business trend referring to human categories (Table 1 ).
Table 1: Global Business Trends in Explaining the Status of Human Categories []]

\begin{tabular}{|c|c|}
\hline The new business trend & $\begin{array}{l}\text { Features of the new trend in } \\
\text { terms of human status }\end{array}$ \\
\hline $\begin{array}{l}\text { Internet of me } \\
\text { (personalized world) }\end{array}$ & $\begin{array}{l}\text { "Internet of me" is used to } \\
\text { identify consumer preferences. } \\
\text { In this new paradigm, smart } \\
\text { devices decide on their } \\
\text { customers' desires. It is essential } \\
\text { for any business to identify an } \\
\text { experience that is valuable to the } \\
\text { customer. }\end{array}$ \\
\hline $\begin{array}{l}\text { outcome-based economy } \\
\text { (Achievement-centric) }\end{array}$ & $\begin{array}{l}\text { In this paradigm, digital power } \\
\text { tools can make economic } \\
\text { conclusions and create a new } \\
\text { business model that is looking to } \\
\text { sell resolutions and results } \\
\text { rather than just products and } \\
\text { services. In this perspective, } \\
\text { technologies such as the } \\
\text { Internet, mobile, cloud } \\
\text { computing, computing, and } \\
\text { analysis are a bridge between } \\
\text { digital companies and the } \\
\text { physical world, so that } \\
\text { businesses can understand just } \\
\text { what they want to do, rather } \\
\text { than delivering products and } \\
\text { services. What customers really } \\
\text { want and what results they } \\
\text { expect. }\end{array}$ \\
\hline $\begin{array}{l}\text { evolution/transformation } \\
\text { on the platform } \\
\text { (introduction of } \\
\text { ecosystems, redefinition } \\
\text { of industry) }\end{array}$ & $\begin{array}{l}\text { Platform based ecosystems are a } \\
\text { necessity to stay in the } \\
\text { competition. The boundaries of } \\
\text { the industry are lifted and the } \\
\text { industries take on a new form of } \\
\text { internal cooperation and } \\
\text { communication. Most } \\
\text { importantly, the features of this } \\
\text { new perspective, in addition to } \\
\text { the variety of new industries, are } \\
\text { based on the needs of the day, } \\
\text { the speed of formation and } \\
\text { responsiveness to the market }\end{array}$ \\
\hline $\begin{array}{l}\text { Intelligent organizations } \\
\text { (massive data, smarter } \\
\text { systems, better business) }\end{array}$ & $\begin{array}{l}\text { Intelligent soft wares that have } \\
\text { power of processing and } \\
\text { providing analytical and } \\
\text { cognitive technologies are used } \\
\text { for better predictions and more } \\
\text { accurate programming. In fact, } \\
\text { software is believed to be } \\
\text { capable of learning and adapting } \\
\text { to change with the world }\end{array}$ \\
\hline $\begin{array}{l}\text { A new conception of labor } \\
\text { (the blended workforce in } \\
\text { the digital world) }\end{array}$ & $\begin{array}{l}\text { In the past, machines were used } \\
\text { to perform better and faster } \\
\text { tasks. But the new challenge is } \\
\text { humans - machines working } \\
\text { together. } \\
\text { In integrated digital and human } \\
\text { workforce, advanced robots, } \\
\text { smart devices and wearable } \\
\text { technologies provide new } \\
\text { opportunities for businesses to } \\
\text { empower their workforce. }\end{array}$ \\
\hline
\end{tabular}

These business trends have led to many transformation that have changed the definition of "health" and the health experience in humans. Activities in the field of health are driven by a combination of technological, economic and social forces. In outcome-based economy, the patient- 
centered approach, new targeted treatment and smart diagnosis are emerging in which financial incentives are value based on outputs (products/services). That is, the results of work and its value presented brings more health to patients and more benefits to the entire health care system. On the other hand, patients who are aware of advanced technologies play an important role in their health. Many factors are catalyzing this change, including the availability of genomic, health, and lifestyle data, and an abundance of technology solutions that help patients monitor, measure, and adjust their habits to improve their health and outcomes of treatment []]. Accordingly, the efforts of major healthcare companies to deliver their service-oriented goals are to provide a new definition of the market focusing on value-based models of performance. To achieve these goals, technologies such as the computer-brain user interface, smart robots, intelligent consultants etc., all of which are in some way connected with humans, are being used.

\section{Business Transformation Processes on the Internet of Things (IOT)}

So far investments on the Internet have focused more on the digitization of operational processes and automation of existing business processes rather than on truly transforming industries by creating entirely new revenue streams and business models. In the near future, human beings will face a number of very important processes in a new era of transformational IoT:

1. Artificial intelligence, fog, and block chain are converging to become the key technologies for IoT transformation.

2. Co-everything is the new normal is driving the "coeconomy".

3. The world is marching toward open standards, open architectures, and interoperability, to create a framework and common architecture in a participatory ecosystem.

4. Security is the make-or-break factor for IoT. A big challenge called security, weakness or strength in the IoT

5. Governments are stepping in to regulate IoT security, privacy and standards.

6. IoT revolution in data analytics [9]].

As these trends show, the focus of IoT is moving from enhancing efficiency to creating new value in participatory, transparency, security, laws and regulations. It seems that as the models and values changed in the business through Internet technology, the world and lifestyle of humans will also undergo huge changes in the future. Activities in this great global network in the future, called the Internet of Humans, will create a new concept in the economy called "our economy" or " crowd economy." The economy, with the help of the infrastructure provided by human internet, will re-shape the market, change the way it interact and operate, and make new resources available. In this kind of economy, there is no single unit, but it transforms platforms, industries and organizations into dependent ecosystems and plays a role in each other's cooperation. Hence, there is no other distinct boundary between them. The health area is no exception to this, and it can take effective measures from the emerging Internet phenomena of humans and our economy in terms of universal coverage of health (UCH) [10].

\section{Key areas of change in health and medical care}

One of the major goals of health care in the 21st Century can be to improve the patient's experience of health care (such as quality and satisfaction), improve community health and reduce the per capita cost of treatment and health care services. There is a growing need for affordable healthcare across all nations and social classes.

The traditional business models often tend to determine price of healthcare for the upper classes, and those in lower socio-economic classes are usually expected to be the responsibility or burden of the government/public sector. With the rise of high technological innovations in healthcare and healthcare trends such as rising healthcare inflation, the market often produces goods that are beyond the affordability for most people [11]. This alignment of services and products has focused on three key areas of the use of information technology in health, the collection and use of information and the provision of new payment models in the new ways of health care (Fig 1) [12].

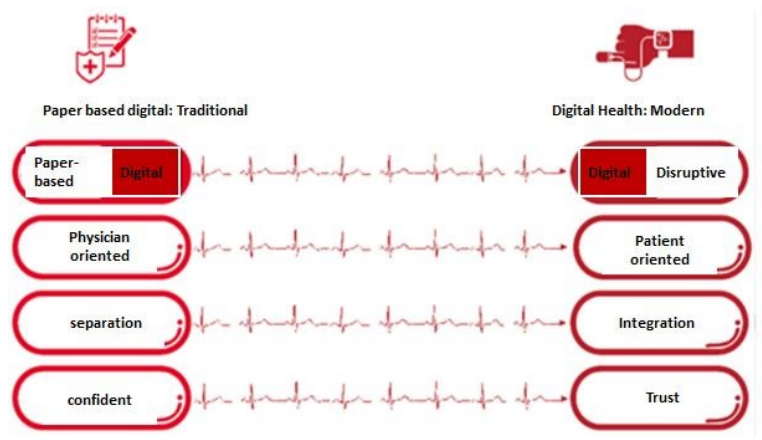

Fig 1: Key Elements of the New Digital Health Model [1ㅡ]

Accordingly, the new model of digital health is based on four components:

1) Disruptive: Business transformation through innovative models that are not exist in current markets.

2) Engagement: Enabling patient-centric digital interactions between clients and consumers 
3) Integration: Provides integrated access to health information through various systems and devices.

4) Trust: Ensuring secure information in a digital age to inspire trust in the providers by the customers

\section{MATERIAL AND METHODS}

The present article is descriptive and qualitative in terms of the purpose of the research. The method and tools are intended to collect information, analyze documents and library documents, and study the types of search engines and databases. In this regard, the proposed framework was reviewed, adapted and deduced from the studies carried out in the field of health and information technology. The evaluation of the proposed framework is based on the integration and consistency among the proposed framework components. Within this framework, there is a link between the macroeconomic policies of each country, existing enablers, control policies, the creation of key and transformative opportunities, and ultimately the appropriate business in the health field.

\section{A proposed framework for supporting} healthcare business in Internet of human ( $\mathrm{IOH})$

Creating a user-centric platform ecosystem based on interoperability data has led to the development of value-based business models based on patient experience outcomes. Some of these emerging business models are []ㅡ:

1. Lean Innovation: rapid growth challenging for existing cost structures, productivity, and operational models

2. Value Innovation: Improve patient outcomes at the center of their strategy and system efficiency through the convergence of digital equipment and services with clinical processes.

3. Around-the-patient innovation: Improve patient value and outcomes at the center of their strategy, leveraging analytics to create novel specialty therapeutics and complimentary services. 4. New health digitals: non-healthcare companies that change the how and where of patient care through cross-industry collaboration, rooted in digital innovation [ㅁ] .

In this way, the move to a value-creating has developed new roles in the value chain ecosystem. Customers/patients, through the innovative solutions provided by innovative companies, acquire special capabilities in the field of health, as a result of this awareness of the entire industry; there is no way to revise their traditional methods of business. Because the new generation of customers/patients will be able to make intelligent choices by comparing the performance of providers, predicting corporate value creation. Information-driven care instead of memory based medicine, personalized care for general treatment, , fully engaged consumer/patients rather than passive patients, rewards for receiving outcomes and rather than reimburse for services, and establishing a community health care system, rather than carsick care activities, are all changes that have taken place in the information age [13]. Until now, in traditional ways, emphasis was on revenue, market share and gross margin. But in the value-driven direction, the emphasis is placed on increased patient value, increased provider value, and increased payer value. In the emerging healthcare ecosystem, value propositions are based on delivering health-based services based on the use of connected devices, sensors, services and social partnerships.

\section{RESULTS}

In the proposed framework, it has been well demonstrated that, based on the macro policies of the health field in each country (areas of action), it is possible to use technological enablers and to create key and transformative opportunities within the framework of key controllers. These transformative opportunities in the six areas are: Create New Products \& Services, create or destroy of the industries, the shift value within, across industries, change the nature of control point (customer/patient), transform how work is done. The most important feature of the proposed framework is its ability to adapt to the needs of each country. In the field of action, the policies in the field of public health (effective coverage and quality management of services, the future of technologies used in the field of health, financial considerations, etc.) can be tailored to the needs of the country.

As an example in Iran's Health System Transformation Plan (HSTP) implies to expand access to healthcare services, reduce the catastrophic and impoverishing out-of-pocket (OOP) payments, promote equity and improve the quality of healthcare services [14]. The technologies that will be used must be tailored to the health financing framework of the health service for all people. For example, cloud services could be considered as one of the requirements of this plan, or the governance on the drug supply chain via block chain could be proposed to drug dispensing to patients. Also, the technologies used, it provides a good opportunity for service management, and instead of investing in healthcare hardware, using inexpensive IT equipment (and even setting up the next-generation industries) for care and prevention Has led to a reduction in the cost of transportation.

Or, as an example, in relation to the HSTP, a reverse innovation approach can be used to provide investment opportunities for industries that need a wider market. Promoting affordable health care in all countries and at all levels of the social class is a general need. Therefore, the use of information 
technology management and the application of advanced business models to increase affordable access to health care services, implement valuebased care and improve the return on investment, and can be used in this area, Significantly affect the economy of a country. Another important point in the proposed framework is the possibility of involvement of other relevant businesses in the field of health. Healthcare businesses need to use new models adapted to advanced technologies in order to maintain competitiveness and improve their position in new markets. Some models include [11]:

- Reverse Marketing: Instead of fixing prices by vendors and providers, the price is passed through potential customers in the bidding process, placing a high emphasis on the reservation price that individuals are willing to pay.

- Sachet Marketing: Daily and cost-effective pricing for the poor class of society .In most rural countries, citizens live on a day-by-day sustenance where earnings barely meet the demands of personal needs and daily requirements.

- Volume Based: Reducing product / service cost structure with the goal of obtaining a high volume of consumer. By increasing volume, fixed costs are spread over a larger number of people, allowing lower costs yet sustainable profit margins for businesses.

- Reverse Innovation: Low-cost product development for developing countries and to serve low-income customers who enter the developed countries after entering developed countries and gaining business success

- Frugal Innovation: Innovation in which the constraints of structural financial resources turn into opportunities and benefits. With frugal innovation, novel solutions can be used as alternatives to reduce the often huge cost of current healthcare offerings.

- Glocalisation Local partnerships through joint ventures: while benefiting from the benefits of the global trend, local opportunities should also be considered

In the proposed framework, using the above models as a combination or package of two or more models in delivering targeted solutions in order to aimed at delivering targeted solutions to achieve favorable health outcomes. For example, the use of reverse pricing and bag marketing creates a sustainable income from turning retail services into optimal health solutions by increasing market share. These two business models change the locations of producers and consumers as whereby it is focusing on adding value to the customers. On the other hand, volume-based models alone may not guarantee the success for larger markets as there may be an overreliance on the pooling of risks and resources among different stakeholders. Frugal innovation and reverse innovation may be useful at creating low-cost and effective alternatives in many emerging economies but their success is largely dependent on the constant nurturing of local talent. Thus, globalization and local partnerships come into play, which present significant opportunities for businesses to redesign and promote healthcare products through convergence and integration, suitable for countries across various ethnicities and cultures

\section{DISCUSSION}

The healthcare industry has been very successful in terms of the adoption of the Internet of Digital (IOD) and the Internet of Things (IOT). In the IoD and IoT generations, focus has been on processes. Efforts to build and manage integrated health and to address all kinds of concerns continue, especially, the stakeholders privacy. The advent of the Internet of Human (IoH), with a value-based approach in the near future, will also protect their rights, due to changing values and changing the identity of patients while providing services based on human.

In this paper, a framework was developed to examine the health industry in the context of IoHs and IoT, introducing technological solutions and new business models for supporting IoH's human health business in the emerging world of Internet of Human (IoH).

\section{CONCLUSION}

The most important achievement of this framework is the creation of an integrated and coherent policy among the country's macroeconomic policy, technological empowerment, controlling factors in human areas and ways to create key and transformative opportunities. So that each country can change the way its macro policies can use advanced technologies to maintain human dignity (Table 2).

For a limited example, the role of this framework was raised in relation to the Iran's Health System Transformation Plan (HSTP) and the status of the use of technology in the introduction of the framework. This example illustrates the using trend of this framework, although designing this framework based on the proposed framework requires more extensive research. 
Table 2. Summary of the results of the proposed framework for the formulation of macroeconomic health strategies with respect to Internet of Things (IOT) [15]

\begin{tabular}{|c|c|c|}
\hline Aim & $\begin{array}{l}\text { Health } \\
\text { Strategies of the } \\
\text { Country }\end{array}$ & Determinants \\
\hline \multirow{4}{*}{$\begin{array}{l}\text { Creating } \\
\text { Integration } \\
\text { Among } \\
\text { Health } \\
\text { Strategies } \\
\text { In a } \\
\text { Country }\end{array}$} & $\begin{array}{l}\text { Recommended } \\
\text { Areas for Action }\end{array}$ & $\begin{array}{l}\text { Everything that needs to } \\
\text { be done in order to } \\
\text { accelerate the } \\
\text { development and } \\
\text { adoptionof the Internet } \\
\text { by humans in public } \\
\text { health policy makers, } \\
\text { such as effective coverage } \\
\text { of services, quality } \\
\text { service management, } \\
\text { healthcare horizons, } \\
\text { financial protection, etc. }\end{array}$ \\
\hline & $\begin{array}{l}\text { Key } \\
\text { Opportunities } \\
\text { and } \\
\text { Transformations }\end{array}$ & $\begin{array}{l}\text { Creating new products } \\
\text { and offering new services } \\
\text { Creating or destroying } \\
\text { the industry } \\
\text { Shifting Value within } \\
\text { Across industies } \\
\text { Change the nature of } \\
\text { control points (customer } \\
\text { / patient) } \\
\text { Redefining role / value of } \\
\text { processes, data, } \\
\text { infrastructure } \\
\text { Transforming how work } \\
\text { is done }\end{array}$ \\
\hline & Key inhibitors & $\begin{array}{l}\text { Security } \\
\text { Legacy and outdated OT } \\
\text { \& infrastructure } \\
\text { technologies } \\
\text { - } \\
\text { Interoperability } \\
\text { Privacy } \\
\text { New investment } \\
\text { Perceived risks } \\
\text { The Role of Governments } \\
\text { Law and regulations }\end{array}$ \\
\hline & Key enablers & $\begin{array}{l}\text { The Internet of Things } \\
\text { Cloud } \\
\text { artificial intelligence } \\
\text { Blockchain } \\
\text { Macro data } \\
\text { Digital divide } \\
\text { Networks, standards and } \\
\text { collaboration capabilities } \\
\text { User-centric platform } \\
\text { ecosystem } \\
\text { The collective economy }\end{array}$ \\
\hline
\end{tabular}

\section{AUTHOR'S CONTRIBUTION}

All the authors approved the final version of the manuscript.

\section{CONFLICTS OF INTEREST}

The authors declare no conflicts of interest regarding the publication of this study.

\section{FINANCIAL DISCLOSURE}

No financial interests related to the material of this manuscript have been declared.

\section{REFERENCES}

1. Malekan, S. Donay eqtesad newspaper [Internet]. 2018 [Cited: 1 Jan 2018]. Available from: https://donya-e-eqtesad.com.

2. Shahid Sadoughi University of Medical Sciences. Stable development for Health [Internet]. 2017 [Cited: 1 Mar 2018]. Available from: www.ssu.ac.ir/fileadmin/290toseieh_va_salamat.ppt.

3. Nabiyi, F. Digital transformation in healthcare and medicine. Digital Nameh. 2018; 3: 16-21.

4. Viola R. Internet of humans: How we would like the Internet of the future to be. [Internet] 2017. [Cited: 30 Jun 2017]. Available from: https://ec.europa.eu/digital-single-market.

5. Taj N, Madani A. Requirements and security approaches in the Internet of things, creating an Internet map for information technology objects. Tehran: ICT Research Institute (ITRC), 2017.

6. Internet Society. Paths to our digital future. Intenet Society Global Internet Report; USA: 2017.

7. Ghaderi P, Mohammadian A. A benchmark for the evaluation of the success of business models based on multidimensional platforms. The 3rd National Conference on Information Systems, Tehran. 2016.

8. O'Riordan A, Elton J. Disruptive forces driving a new order in healthcare business models. [Internet] Pharmaceutical Executive. 2016 [Cited: 24 Jun 2017]. Available from: http://www.pharmexec.com.

9. Kranz M. Seven trends changing IoT and the world. [Internet] 2018 [Cited: 5 Jul 2018]. Available from: http://www.maciejkranz.com/seven-trendschanging-iot

10. Ghaderi, P. Electronic business trends in the year of 2015. The 3rd National Conference on Information Systems, Tehran. 2016

11. Deloitte's Future Healthcare centre of Excellence. Healthcare for thr pre-middle class in emerging economies. Deloitte \& Touch Enterprise Risk Services Pte Ltd. 2016.

12. Butler, S. The digital healthcare leap. London, United Kingdom: Pricewaterhouse Coopers LLP (PwC), 2017.

13. Bennetsen H, Dunagan J, Fidler D, Harp G, Jeffery L, Liebhold M. Internet human human Internet. Palo Alto, CA: Institute for the Future (IFTF), 2012.

14. Kolkman L, Fhimss R. The future of the healthcare economy. USA: Mosaica Partners- Himss, 2014.

15. World Economic Forum. Industrial Internet of things: Unleashing the potential of connected products and services. Geneva, Switzerland: World Economic Forum, 2015. 